\title{
SIMULATION BASED DESIGNING OF CONTROL SYSTEMS FOR WIND POWER GENERATION
}

\author{
Guruswamy Revana ${ }^{1}$, D.E.Amrutha ${ }^{2}$, D.Spandana ${ }^{3}$, D.Anusha ${ }^{4}$ \\ ${ }^{1}$ Associate Professor, BVRIT HYDERABAD College of Engineering for Women, Hyderabad, India. \\ ${ }^{2}$ B.Tech., BVRIT HYDERABAD College of Engineering for Women, Hyderabad, India \\ ${ }^{3}$ B.Tech., BVRIT HYDERABAD College of Engineering for Women, Hyderabad, India \\ ${ }^{4}$ B.Tech., BVRIT HYDERABAD College of Engineering for Women, Hyderabad, India
}

\begin{abstract}
${ }^{1}$ guruswamy.rabvrithyderabad.edu.in
216 wh1a0206abvrithyderabad. edu. in

${ }^{3} 16$ wh1a02490bvrithyderabad. edu. in

${ }^{4} 16$ wh1a0206@bvrithyderabad. edu. in
\end{abstract}

\begin{abstract}
Wind power is a domestic source of energy, harnessing a limitless local resource and is a potential source of clean electricity generation. Wind is utilized to create electrical energy by means of the kinetic energy formed by air into movement. This energy is changed to electrical energy by wind speed turbines or also called as wind energy exchange systems. Wind speed power generation creates a progressively more significant position in the method the humans power the world. During the process of wind power generation, a variety of characteristics are to be controlled for efficient working of the system and to avoid failure of continuous power supply. In this project we are aiming to control a few such characteristic such as pitch angle, voltage sag and faults that influence wind power generation. The DC link voltage of the Doubly Fed Induction Generator (DFIG) is also monitored. In this wind turbine system consists of wind turbine, $\mathrm{AC}$ generator and controllers are considered.
\end{abstract}

The major purpose of the paper is to find out the mathematical model of the wind turbine, authenticate it by simulation, and devise a suitable controller to present a common aim of outlook regarding the use of this type of clean energy production. Various rudiments are connected collectively and the complete arrangement is modelled and also simulated. The simulation results verify the accuracy of the mathematical models developed and can be utilized for a improved design of systems. Wind turbines make use DFIG which consists of wound rotor type induction generator and a PWM converter of IGBT bases of AC/DC/AC. The stator winding is connected directly to the $60 \mathrm{~Hz}$ grid while the rotor is fed at variable frequency through the AC/DC/AC converter. The DFIG machinery permits pulling out highest energy from the wind from lowest wind speeds and optimizing the speed of the turbine there by decreasing mechanical stresses on the turbine during gusts of wind. The most favourable turbine speed producing increased mechanical energy for a given speed of the wind which is directly proportional to the wind speed. The other merit of the DFIG expertise is the capability for the converters of power electronics to produce or take in reactive power, thereby reducing the need for putting in capacitor banks as done for the generators of squirrel-cage induction motor type.
Keywords - Controller, DFIG, Power Quality, Simulation, Wind Power.

\section{INTRODUCTION}

With the enhanced diffusion of wind power into electrical grids, DFIG wind turbines are mostly positioned due to their changeable speed characteristics and therefore controlling system dynamics. This feature has shaped awareness in developing appropriate models for DFIG which are to be included in the power system studies. The uninterrupted tendency of having more diffusion of wind power, in current time, has made it essential to bring in new practices. For instance, grid codes are revised to make sure that wind turbines would add to be in command of both voltage and frequency and also to continue connected to the main network subsequent to a disturbance. In reaction to the current grid code requirements, a number of DFIG models were proposed recently, which includes the fullrepresentations which is a fifth order model. These models utilize quadrature and direct components of rotor voltage in a suitable orientation edge to offer speedy regulation of voltage. The third order representation of DFIG which makes use of rotor current, but not rotor voltage as control parameter can also be useful to offer extremely quick regulation of instantaneous currents through the penalty of bringing down the accuracy. Apart from that, the third order representation can be reached by ignoring the rate of change of stator flux linkage, with the known rotor voltage as control parameter. In addition to that in order to represent back to back PWM converters, in the simplest circumstances, it is implicated that the converters are perfect and the DC-link voltage between the converters is invariable. As a result, depending on the converter control, a controllable voltage (current) source can be put into practice to correspond to the process of the converter rotor side of the representation. Nevertheless, in actuality DC 


\section{International Journal of Engineering Technology and Management Sciences[IJETMIS]}

Website: ijetms.in Issue:5, Volume No.4, September-2020 DOI: 10.46647/ijetms.2020.v04i05.019

link voltage does not remain steady however starts rising for the period of fault condition. Consequently, with the above assumption it would not be likely to decide whether the DFIG will in reality trip with the following a fault.

\section{OBJECTIVES}

The main objectives of this project are:

1. Turbine response to a change in wind speed.

2. Voltage sag Effect on the system.

3. Impact of Faults on the system.

Turbine response to a change in wind speed:

Originally, wind speed is put at a certain value at a given time, wind speed raises rapidly as the time increases. In simulation we observe the signals and monitor the wind turbine voltage, current, produce reactive and active powers, turbine speed and DC bus voltage. Afterwards the pitch angle is enhanced as of its preliminary value in order to control the mechanical power.

\section{Simulations of a voltage sag on the system:}

We will at this moment observe the effect of the voltage sag which results from a remote fault on the system. Firstly, we work on step block of the wind speed; we hinder the wind speed step by altering the concluding value to beginning value. Then a voltage drop is planned to happen at time and monitor the system voltage and current along with the speed of the motor. Then the system for protection trips due to the low voltage detected in the system. By means of voltage regulation, such trips can be barred.

\section{Impact of Single phase to Ground Fault:}

Finally, it is observed that impact of a single phase-toground fault occurred on a line. It is also checked with that of the fault planned to relate a single-phase to ground fault at that particular time. When the voltage value is above the under-voltage protection threshold the wind farm stays in service even under fault conditions. However, if the VAR regulation mode is utilized with reactive power at zero, the voltage comes down under threshold value and the under voltage protection trips at the wind farm. It is observed that the there is increment in the turbine speed. Therefore, the there is a raise in pitch angle control in order to control the speed.

\section{Simulation MOdEl OF THE SYSTEM}

We have discussed here the basic operation of DFIG and its controls using AC/DC/AC converter. First, we simulated a wind turbine driven isolated (not connected to grid) induction generator. But for finest efficiency DFIG system is utilized when it is associated to grid side and has improved control. The converter connected to rotor side (RSC) generally offers active and reactive power control of the system while the converter towards grid side (GSC) remains the voltage of the DC link steady. So in conclusion, the simulated grid side and wind turbine side constraints and the resultant results have been exhibited.

The simulation model is a discrete-time narration of the Wind Turbine DFIG (Phasor Type) of MATLAB/Sim Power Systems. Here the protection system is taken in reflection which provides a trip signal to the system during the fault (single phase to ground fault) on the system. The faults can happen when wind speed decreases to a lesser cost or whenever it has unrelenting fluctuations.

The DFIG is capable to offer a significant input to grid voltage bear during short circuit periods. Taking into deliberation the results, it can be concluded that DFIG established to be more consistent and steady system when associated to grid side with the appropriate control system for a converter. Wind has plenty of prospective in it and if appropriately connected then it can aid explain the energy calamity in the planet.

The learning of wind turbine and its distinctiveness demonstrated that proper design and usage will get maximum output. The circuitries of power electronics had aided the perception of wind power in a large scale. Without them the concept presented would have been too costly and implausible. With the converters and thyristors being utilized not only the processed are smoothened but also the efficiency has been improved to enormous extent.

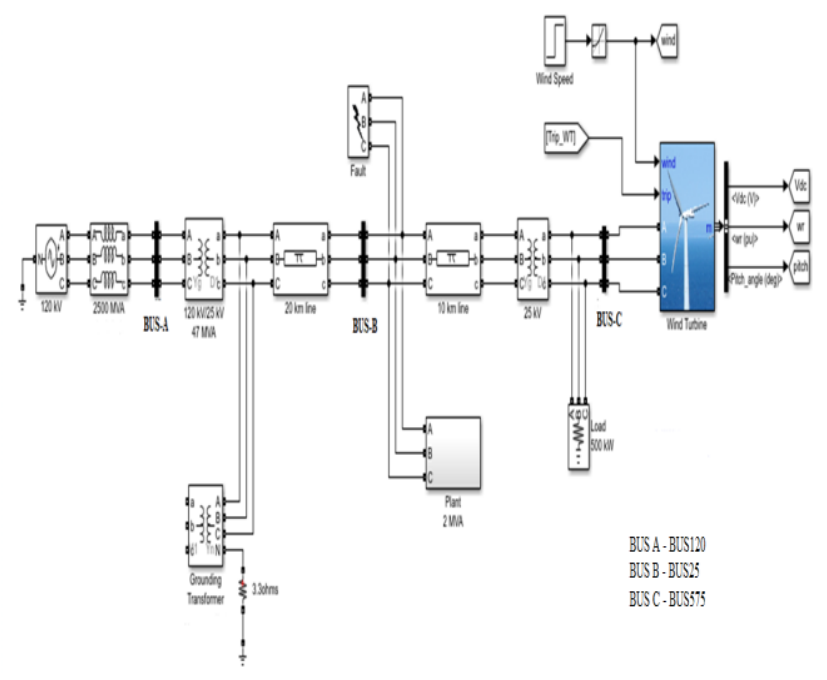




\section{International Journal of Engineering Technology and Management Sciences[IJETMSS]}

Website: ijetms.in Issue:5, Volume No.4, September-2020 DOI: 10.46647/ijetms.2020.v04i05.019
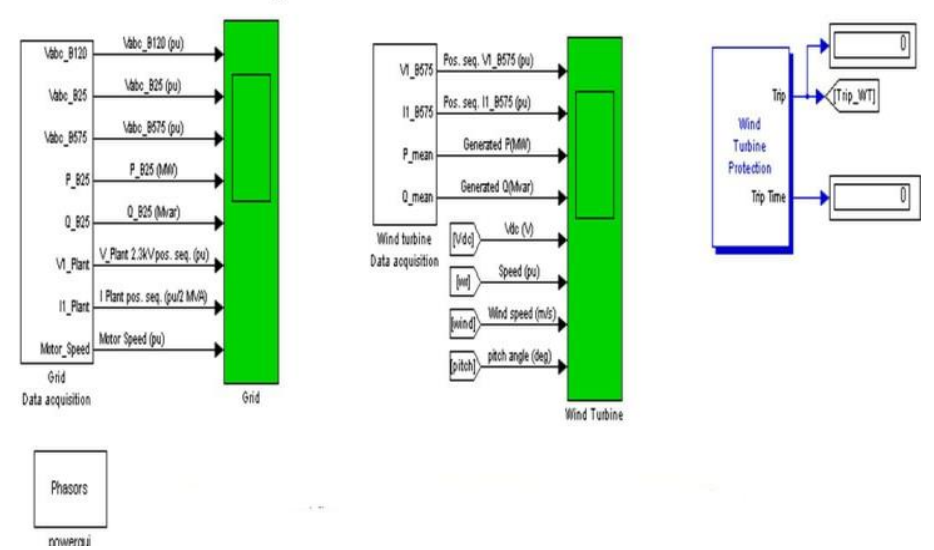

Fig1. Simulation Model of the System 3.1 TURBINE RESPONSE TO A CHANGE IN WIND SPEED

In the "Wind Speed" step block specifies the wind speed. To begin with, the speed of wind is set at $8 \mathrm{~m} / \mathrm{s}$, at the time $\mathrm{t}=5 \mathrm{~s}$, wind speed raises abruptly at $14 \mathrm{~m} / \mathrm{s}$. Simulation is started to monitor the signals on the "Wind Turbine" scope observing the voltage, current of wind turbine, produced active and reactive powers, DC bus voltage and speed of the turbine.

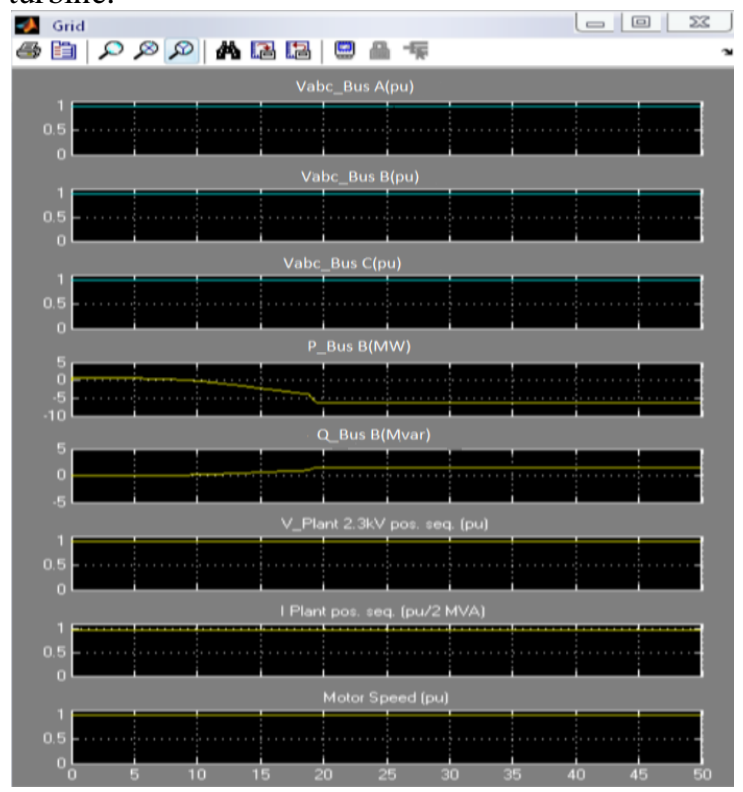

Fig. 2 Output 1 for Objective 1

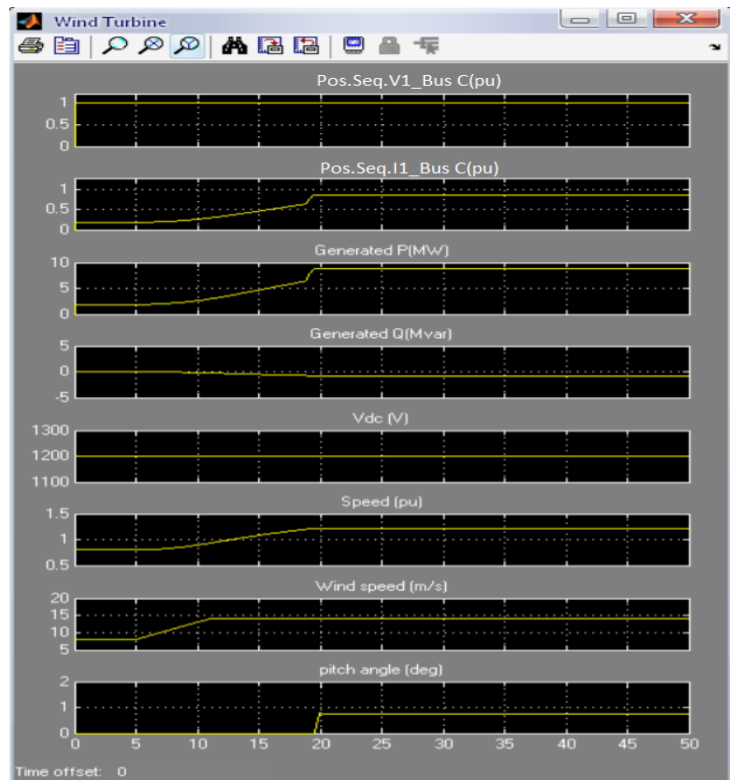

Fig.3 Output 2 for Objective 1

At $\mathrm{t}=5 \mathrm{~s}$, the produced active power begins escalating effortlessly (along with the speed of the turbine) to arrive at its rated value of $9 \mathrm{MW}$ in about 20s. During that time period the speed of the turbine increases from $0.8 \mathrm{PU}$ to 1.21 PU. Firstly, the turbine blades are zero degree for the pitch angle and the operating point of turbine follows the red curve in the turbine power characteristics. It is considered up to the point $\mathrm{D}$.

Afterwards the pitch angle is improved from 0 deg to 0.76 deg in order to border the mechanical power. The reactive power is controlled to maintain a 1 PU voltage. At nominal power, the wind turbine absorbs 0.68 MVAR (generated $\mathrm{Q}=-0.68 \mathrm{MVAR}$ ) to control voltage at 1PU. If we alter the mode of process to "VAR regulation" with the "Generator reactive power Q reference" is set to zero, it is observed that voltage enhances to $1.021 \mathrm{PU}$ after the wind turbine produces its supposed power by unity power factor.

In this mode the wind turbine speed varies very much starting from $0.7 \mathrm{PU}$ to $1.6 \mathrm{PU}$ and then tending to stabilize at 1.0 PU. At about $\mathrm{t}=12 \mathrm{~s}$ there is enhancement in the angle of pitch abruptly. 


\section{International Journal of Engineering Technology and Management Sciences[IJETVIS]}

Website: ijetms.in Issue:5, Volume No.4, September-2020 DOI: 10.46647/ijetms.2020.v04i05.019

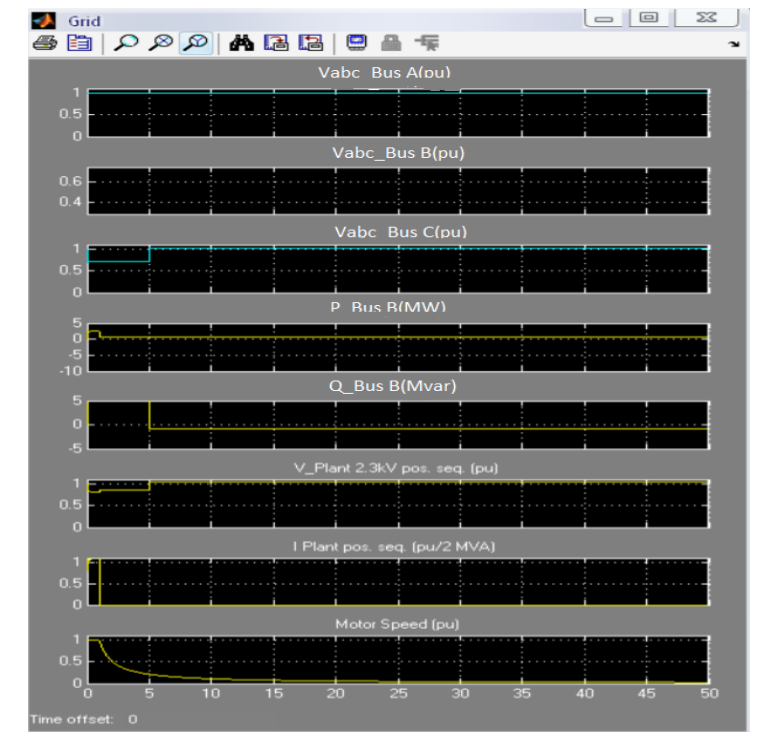

Fig.4 Output 3 for Objective 1

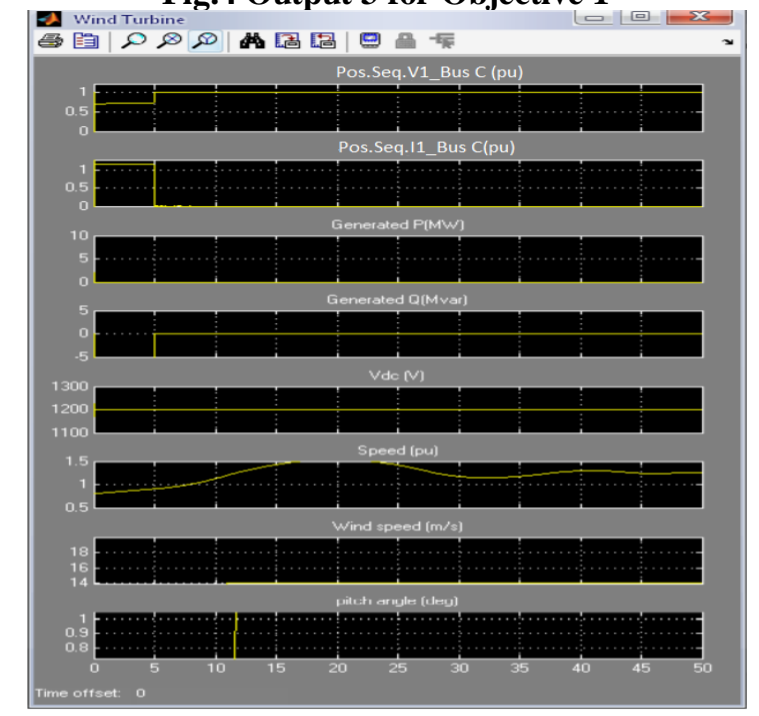

Fig .5 Output 4 for Objective 1

\subsection{SIMULATION OF VOLTAGE SAG ON THE} 120KV SYSTEM

It is experimentally verified that the effects of voltage sag are result from a far-off fault on the $120 \mathrm{KV}$ system. Initially, in the wind speed step block, Wind speed step is disabled by changing the ending value from 14 to $8 \mathrm{~m} / \mathrm{s}$. Now $120 \mathrm{KV}$ voltage source menu is opened. In the constraint "Time variation of" is selected with "Amplitude" of $0.15 \mathrm{PU}$ voltage drop lasting for $0.5 \mathrm{~s}$ is planned to take place at $\mathrm{t}=5 \mathrm{~s}$.

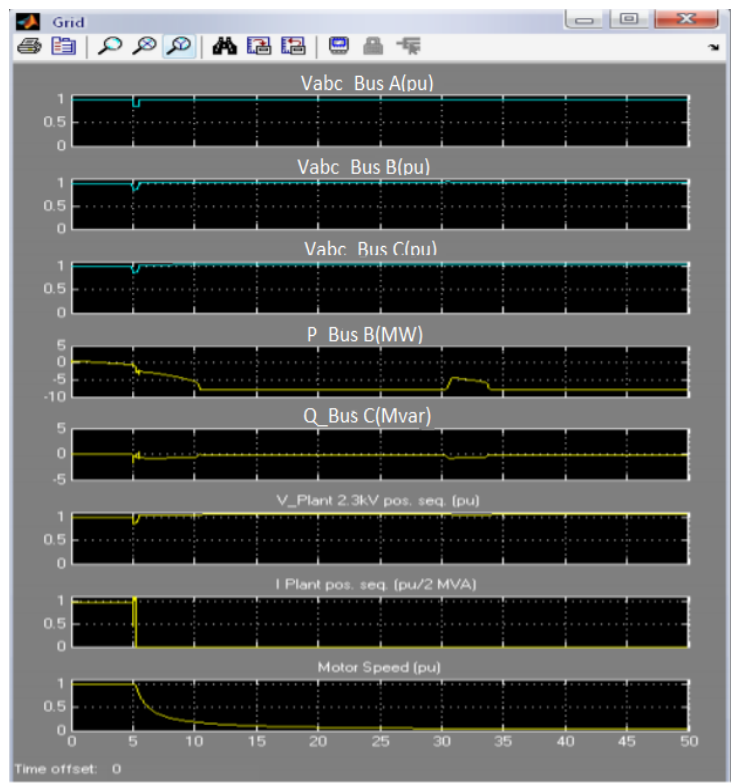

Fig.6 Output 1 for Objective 2

It is made certain that control mode continue to be in VAR regulation with Qref $=0$. Then the simulation is started and opened in the "Grid" scope. It is noticed that the plant voltage and current and also the speed of the motor. It is clear that the wind farm generates $1.87 \mathrm{MW}$. At $\mathrm{t}=5 \mathrm{~s}$, the voltage comes down below $0.9 \mathrm{PU}$ and at $\mathrm{t}=5.22 \mathrm{~s}$, the system of protection trips the plant since an under voltage for greater than $0.2 \mathrm{~s}$ is detected. The plant current comes down to zero value and the speed of the motor comes down slowly, at the same time as the wind farm continues producing at a power intensity of $1.87 \mathrm{MW}$. Later than the plant is tripped, $1.25 \mathrm{MW}$ of power (P Bus B measured at Bus $\mathrm{B}$ ) is given to the grid.

Now, the wind turbine control mode is varied to "Voltage regulation" and the investigation is repeated. It is observed that the plant does not trip anymore. This is for the reason that the voltage aid is offered by the 5MVAR reactive power produced by the turbines of wind at the time of voltage sag which the plant voltage over the 0.9PU protection threshold. The plant voltage at the time of the voltage sag is at the present is $0.93 \mathrm{PU}$. 
Website: ijetms.in Issue:5, Volume No.4, September-2020 DOI: 10.46647/ijetms.2020.v04i05.019

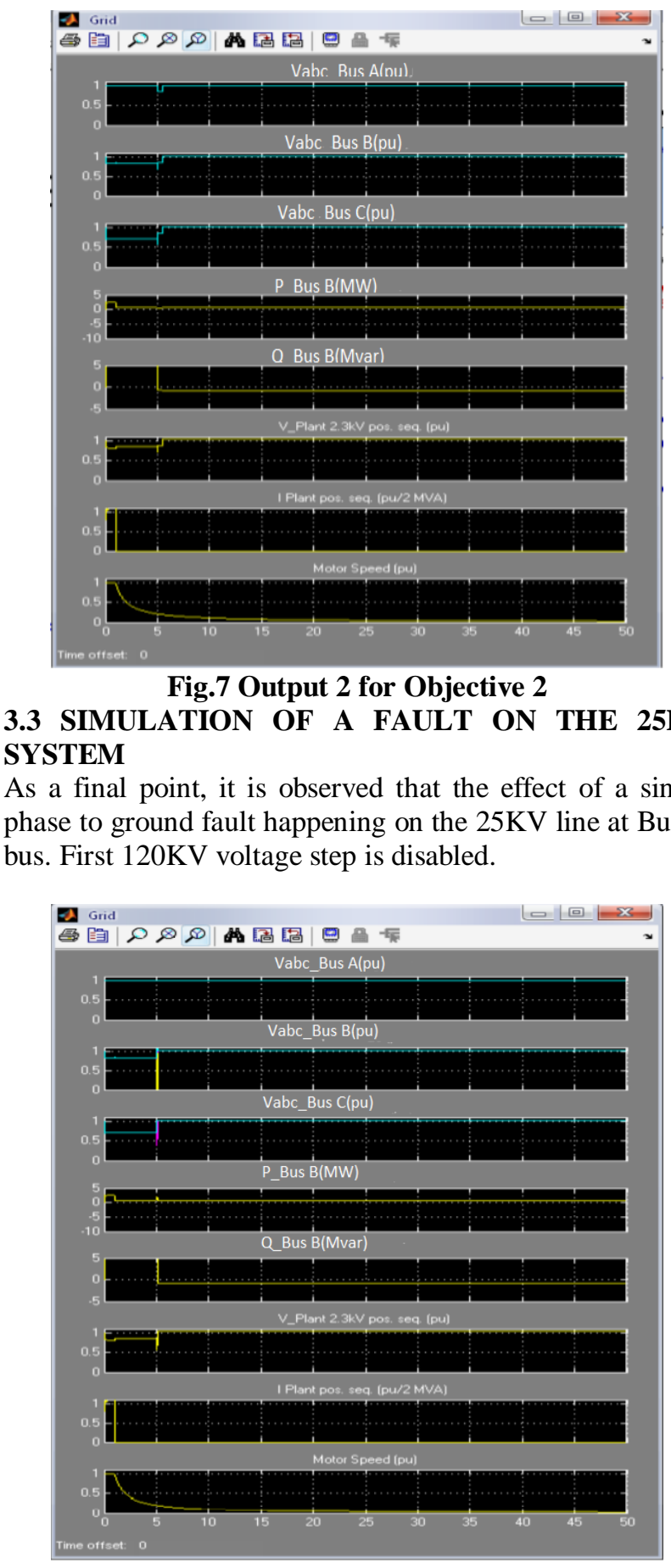

Fig.8 Output 1 for Objective 3

Then "Fault" block menu is opened and "Phase A Fault" is selected. The fault programmed is checked to pertain a 9 cycle single phase to ground fault at $t=5 \mathrm{~s}$. It is noticed that at the time the turbine of the wind is in "Voltage regulation" mode, the positive sequence voltage at the turbine of turbine terminals (V1_Bus C) decreases to 0.8PU at the time of the fault, which is over the under voltage protection threshold $(0.75 \mathrm{PU}$ for a $\mathrm{t}>0.1 \mathrm{~s})$. The wind farm consequently remains in service. On the other hand, if the "VAR regulation" mode is utilized by means of Qref $=0$, the voltage drops beneath $0.7 \mathrm{PU}$ and the under voltage protection trips the wind farm. It is noticed that the speed of the turbine enhances. At $\mathrm{t}=40 \mathrm{~s}$ the pitch angle begins to enhance to limit the speed.

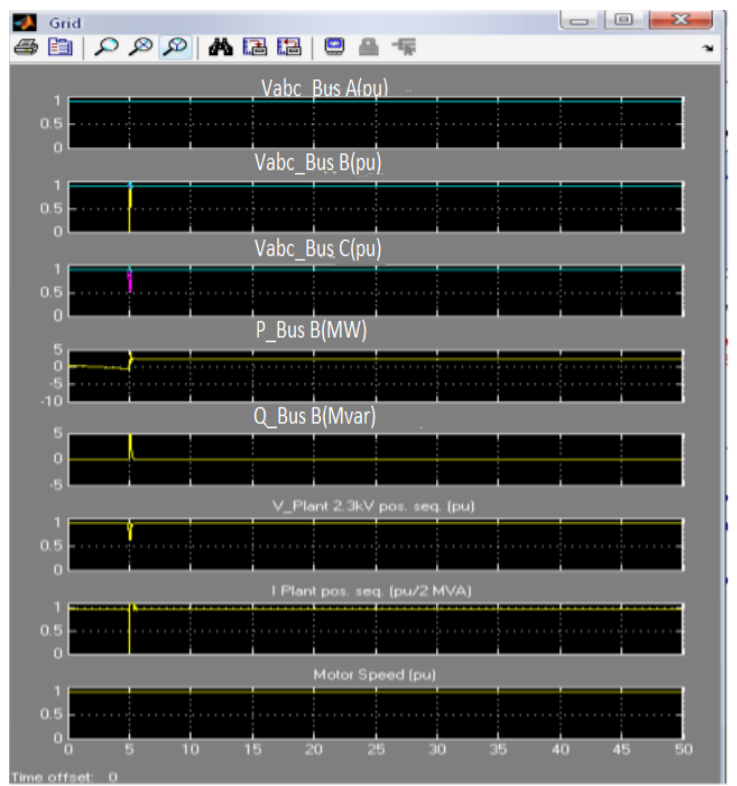

Fig.9 Output 2 for Objective 3

IV CONCLUSIONS

The basic function of DFIG and its controls using $\mathrm{AC} / \mathrm{DC} / \mathrm{AC}$ converter is being discussed in this paper. Initially simulation is completed for a wind turbine driven isolated (not connected to grid) induction generator. Later for better efficiency the DFIG system is utilized, it is connected to grid side and proved to have better control. The RSC more often offers active and reactive power control of the machine while the GSC remains the voltage of the DC link steady. So to conclude grid side and wind turbine side parameters are simulated and the corresponding results have been shown.

The model is a discrete-time version of the turbine of wind DFIG (Phasor Type) of MATLAB/Sim Power Systems. The protection system is taken in consideration which provides a trip signal to the system whenever fault (single phase to ground fault) is there on the system. The faults can happen while speed of the wind speed reduces to a lesser value or has constant fluctuations.

The DFIG is also able to offer a considerable input to grid voltage hold throughout short circuit phase. By considering all these points, DFIG shows to be further more reliable and stable system while connected to grid side with the appropriate converter control system. Wind energy has tremendous potential and if correctly harnessed then it can aid to solve the energy calamity of the globe. 
Website: ijetms.in Issue:5, Volume No.4, September-2020 DOI: 10.46647/ijetms.2020.v04i05.019

The study of turbine of the wind along with its characteristics resulted that it can be properly designed and utilized to obtain the highest output. The circuitries of the power electronic devices aided the concept of wind power in a big way. Without power electronics, this concept would be too costly and implausible. With the usage of thyristors and converters, the operations were smoothened and the efficiency was enhanced to a immense extent.

\section{REFERENCES}

[1] Wan, Lifeng Cheng, and Xiaoling Sheng "Effects of Yaw Error on Wind Turbine Running Characteristics Based on the Equivalent Wind Speed Model Shuting" School of Energy Power and Mechanical Engineering, North China Electric Power University, Baoding 071003, China.

[2] Andrew Clifton, Paul Fleming, Levi Kilcher, Julie K. Lundquist "Effects of Changing Atmospheric Conditions on Wind Turbine Performance" National Renewable Energy Laboratory, Golden, Colorado.

[3] Y. Lei, A. Mullane, G. Lightbody, and R. Yacamini, "Modeling of the wind turbine with a doubly fed induction generator for grid integration studies," IEEE TRANSACTIONS ON ENERGY CONVERSION, no. 99, pp. 1-8, 2005.

[4] A.D. Hansen, N. A. Cutululis, B. Barahona and H. Markou, "Impact of fault ride-through requirements on wind turbine structural loads", European Wind Energy Conference (EWEC) Warsaw - Poland, 2010.

[5] H. Amarís, "Power Quality Solutions for Voltage dip compensation at Wind Farms", IEEE Power Engineering Society General Meeting, 2007.

[6] F. Zhou, G. Jos, and C. Abbey, "Voltage stability in weak connection wind farms," in Power Engineering Society General Meeting, vol. 2. June: IEEE, San Francisco, California, USA 2005, pp. 1483-1488.

[7] www.windpower.org

[8] www.arrc.ou.edu

[9] https://www.ijert.org/assesment-of-wind-energy-potential-fromhighways

[10] https://www.slideshare.net/rudreshsj/wind-energy-potential-fromhighways

[11] www.davidarling.info/encyclopedia

[12] https://www.semanticscholar.org/paper/Voltage-Stability-Analysisof-Wind-Farm-Integration-Chi-

Liu/c7e8cc8b0dcfe9a8a2a9fdd7907aa99b47400f49 